\title{
Libraries and librarians as coadjutants in the editorial process of scientific publications - reaffirming a proposal
}

For a long time, I have been describing the trajectory of the Brazilian Journal of Pharmaceutical Sciences. During those years, we have been discussing about our contribution to the promising scenario of Pharmaceutical Sciences. Being optimist, we have shown the evolution of the publication through the implemented editorial improvement. We keep discussing optimistically many important topics, presenting our challenges, history, process of internationalization and our thinking about many questions.

Now, we are facing other reality, with new reflections toward a new phase in the processes of BJPS edition.

According to Serradas (2011), there are new forms of librarians’ participation today. He defends the "embedded librarians, integrated and close to researchers, promoting scientific knowledge generation and actively involved in scientific communication. This reminds us the BJPS trajectory that has been counting on the active participation of the librarians since its creation. In 1986, BJPS was formally included in the Publication and Divulgation Service, part of the Library and Documentation Division of the Chemistry and Pharmacy Institutes. We can say that this was a pioneering action considering the librarians' profile now defended by the international community. Due to a professional team of the Library, BJPS conquered a qualified position as the most important scientific vehicle for divulgation of Pharmaceutical Sciences in Brazil.

This fruitful experience emphasizes that we librarians cannot go ahead with the old profile, restricted to being the knowledge guardians, responsible for registration, processing and preservation of the collections, along with being intermediates of information by providing access to documents and assisting the capacitation of the users. Expanding our actuation in the generation and certification of the knowledge is of utmost importance. 


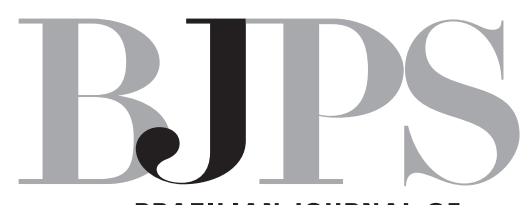

Brazilian Journal of

Pharmaceutical Sciences

We know the information is universally available, independently from the place of access. So, it is very important to redefine the roles of librarians and libraries, as discussed by Crow et al. (2012). Accordingly, North-American libraries have been expanding their roles in academic publications, offering many services as pre-publication and editorial support. In addition, they emphasize the need for a practical orientation about the challenges and opportunities the programs of library-based publication can offer.

Librarians who work on edition have been a link between the scientific editors and the scientific communication media. They promote indexation in the available databases, have the knowledge about the quality required by the indexer organs and ensure the maintenance of a permanent and promising new knowledge information flux. According to this new paradigm, libraries are dynamic centers that can represent this interface. Multi-professional teams could participate in this new scenario, since the publication is open to many other fields, as linguistics, for example. Being able to actively participate in the communication processes, they could be coadjutants in the editorial process.

BJPS statistic data that follow can prove this thesis and we think this is an example to be considered.

The year 2015 was very hard toward advancing BJPS quality as a reliable publication on Pharmaceutical Sciences. The indexers organs are more and more demanding and sustainability has always been a big challenge, but we believe we have conquered national and international recognition. Since 2011, BJPS was included in the Science Citation Index and its impact index advance can be evidenced in Graph 1, which presents statistical data according to Scimago/Elsevier (http:qqwww.scimagojr.com/journalsearch. php?q=q19700182901\&tip=sid).

We received in 2015, 254 submissions and we had 408 processes under analysis (Graph 2). From this total, 138 manuscripts were refused, corresponding to around 34\% of the submitted works (Graph 3). This reflects the severity in the evaluation we have achieved thanks to the reviewers' commitment. It is worth noting that the pre-analysis of the manuscripts either related to formal aspects, by the Executive Editor, or concerning the quality and scope framing, by the Associated Editors, has contributed to these numbers. In 2015, the BJPS had published 94 articles, keeping stble the number of publications (Graphs 4 and 5)

Concerning the origin of the published papers (Graph 6), there was a small increase in those developed by specialists from the University of Sao Paulo in co-authorship with researchers from other Institutions from Brazil and abroad. This reflects the recognition of BJPS also by local community, what is very important in order to reach higher impact indexes according to the indexer organisms. 


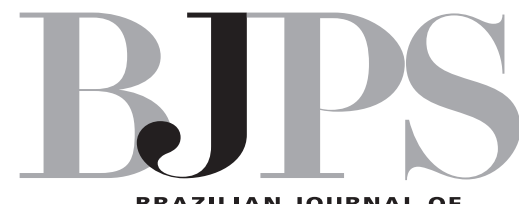

BRAZILIAN JOURNAL OF

PHARMACEUTICAL SCIENCES
Brazilian Journal of Pharmaceutical Sciences

GRAPH 1

Scimago/Elsevier indexes

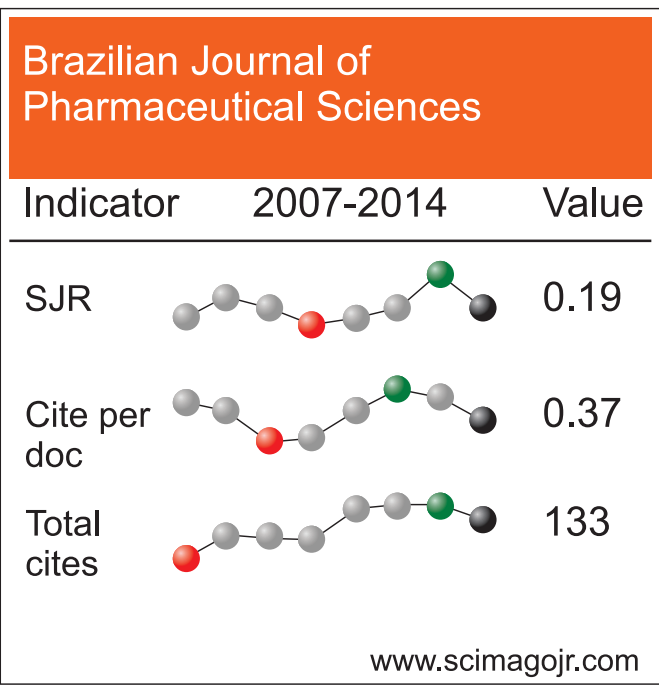

Source: http://www.scimagojr.com/journalsearch.php?q=19848250\&tip=iss\&exact=yes $>$.

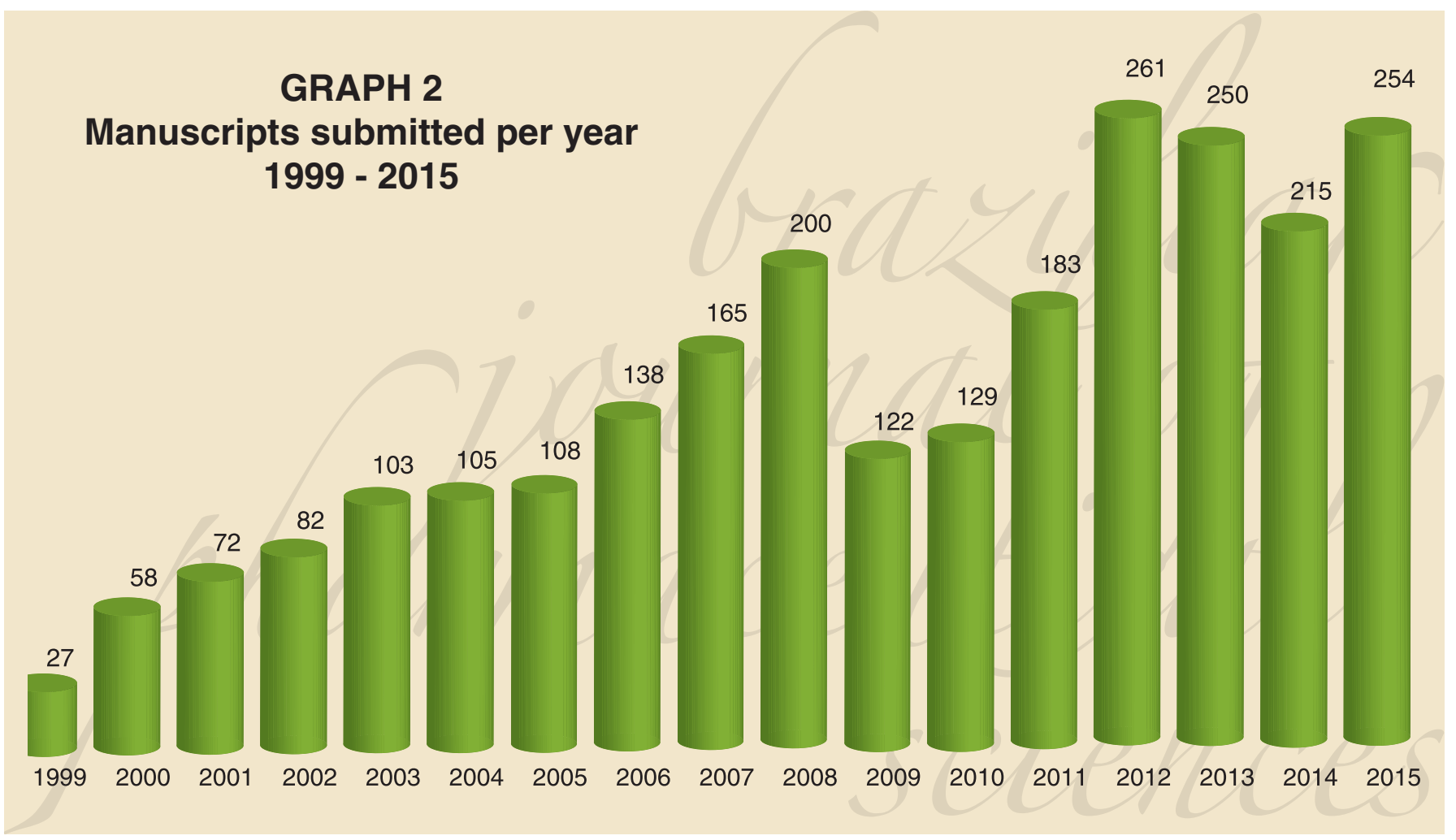




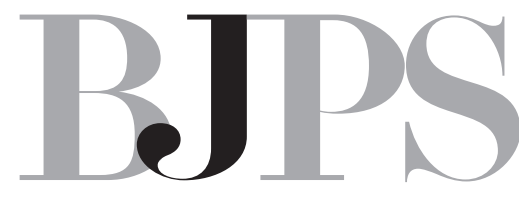

Brazilian Journal of Pharmaceutical Sciences

BRAZILIAN JOURNAL OF

PHARMACEUTICAL SCIENCES

GRAPH 3

Manuscripts refused per year

$2000-2015$
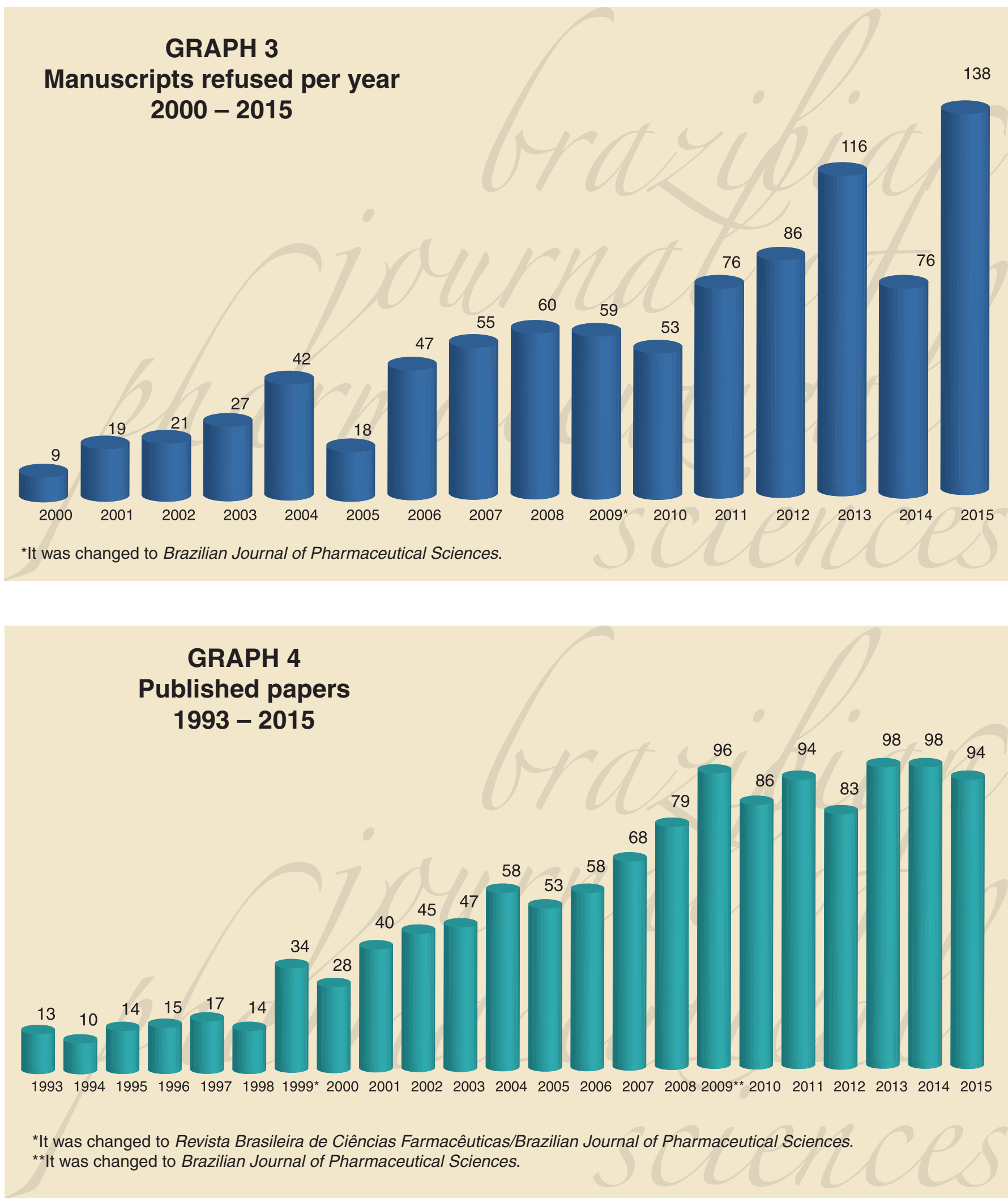


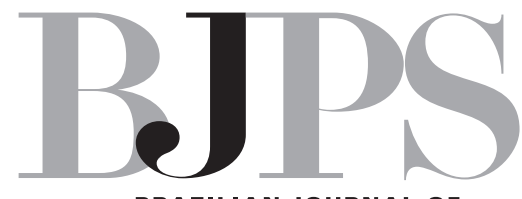

Brazilian Journal of Pharmaceutical Sciences

BRAZILIAN JOURNAL O

PHARMACEUTICAL SCIENCES

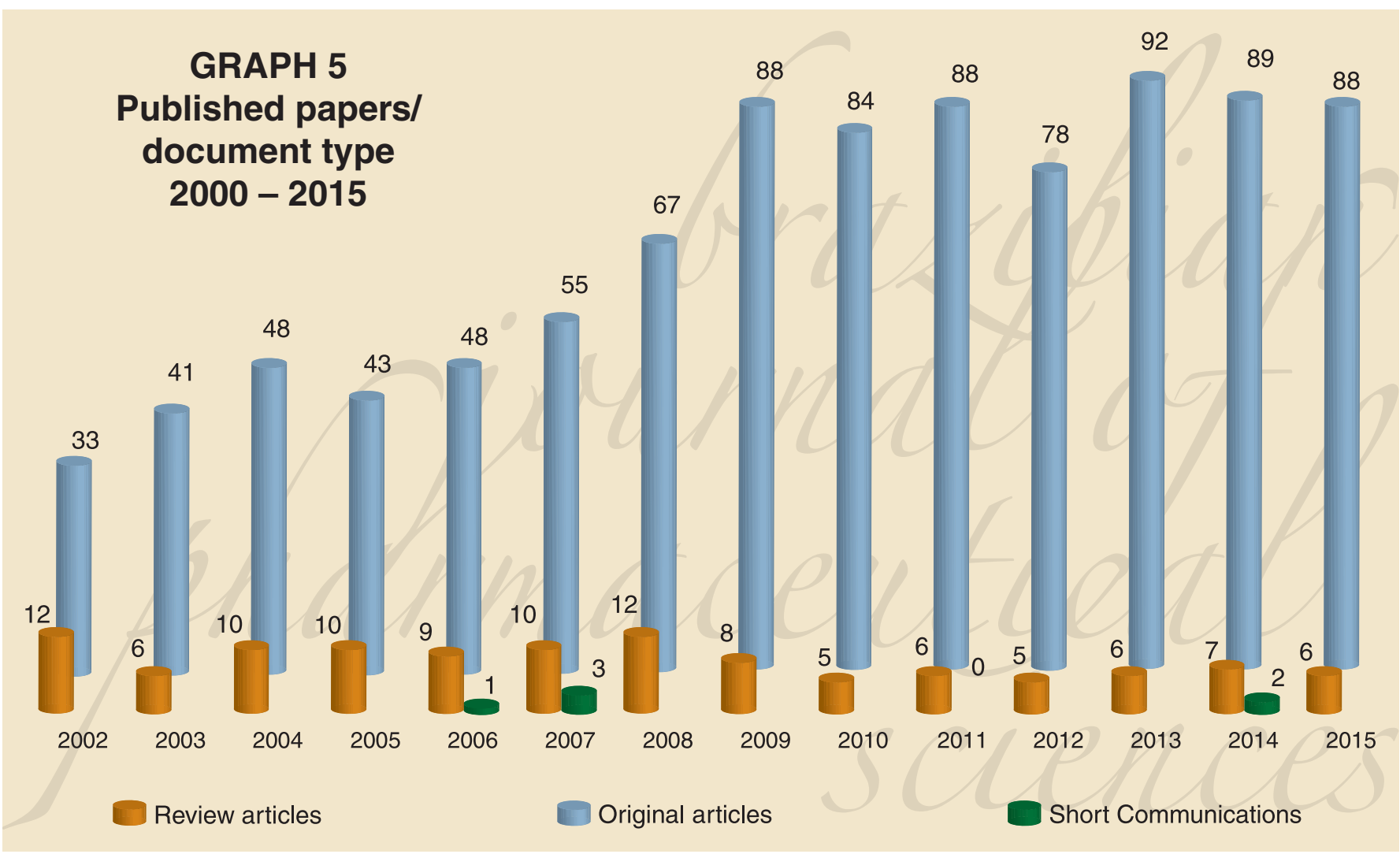

GRAPH 6

Origin of published papers

$1999-2015$

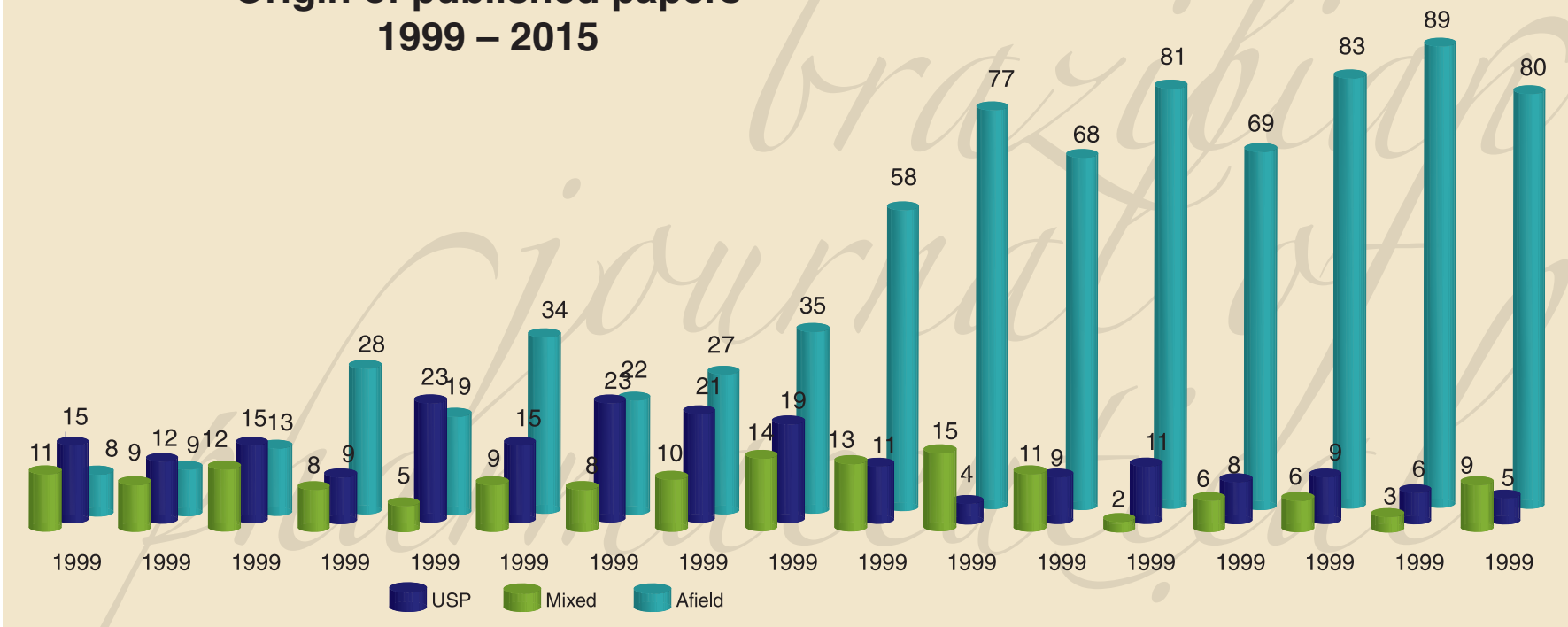




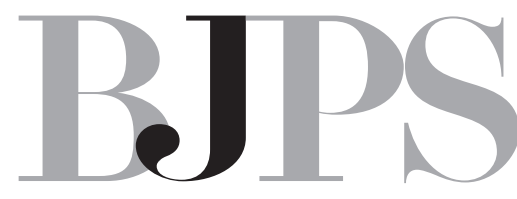

Brazilian Journal of

Pharmaceutical Sciences

Considering the numbers herein presented, one could ask why the discussion about the role of librarians and of the libraries as coadjutants in the editorial process of scientific publications. This reminds us Berthold Brecht words: "What times are those, when we have to defend the obvious?" Questions stand to the statements here presented and we think that this debate can be fruitful. We also believe that any progress is only possible if sustainability and a technical work team are present. This must prevail over a solely work. For this reason, the reflections presented here have the goal of bringing sobriety to future decisions!

I thank the Scientific Editor, Prof Elizabeth Igne Ferreira, who for 20 years has stimulated me in the position of Executive Editor. I also thank the assistant Arina Maria Moreira Sampaio, trainee supported by FIPFARMA, for her dedication, integrity and ethics that triggered her courage for working in arduous situation.

We wish our actions could be directed in favor of the society, generating wealthy, promoting prosperity, inclusion and citizenship for everyone!

\author{
Leila Rangel de Carvalho Aranha \\ Editora Executiva
}

Brazilian Journal of Pharmaceutical Sciences

\title{
REFERENCES
}

CROW, R.; IVINS, O.; MOWER, A.; NESDILL, D.; NEWTON, M.; SPEER, J.; WATKINSON, C.; MULLINS, J.L.; RUST, C. M.; OGBURN, J.L. Library publishing services: strategies for success. Available at: < http://docs.lib.purdue.edu/cgi/viewcontent. cgi? article=1023\&context=purduepress_ebooks $>$. Accesed on: Dec., 2015.

SERRADAS, A. Embedded librarian: relato de uma experiência na Psicologia Brasileira. Psicologia USP, v.22, n.2, p.437-443, 2011.

SCIMAGO/ELSEVIER. Disponível em: <http://www.scimagojr.com/journalsearch.php?q=19700182901\&tip=sid >. Acesso em:

Dez. 2015. 